\title{
Uncertainty on monetary policy and the expectations model of the term structure of interest rates
}

\author{
Carlo A. Favero*, Federico Mosca \\ IGIER, Universita L. Bocconi, via Salasco 5, 20136 Milan, Italy
}

Received 5 September 2000; accepted 8 November 2000

\begin{abstract}
In this paper we jointly estimate a forward-looking reaction function for the 3-month rate along with a term structure relationship linking the 6-month interest rates to current and expected future 3-month rates. In our empirical model, the response of the 6-month interest rates to current and future 3-month interest rates is allowed to depend on uncertainty on monetary policy. The expectations theory cannot be rejected in periods of low uncertainty on monetary policy. (C) 2001 Elsevier Science B.V. All rights reserved.
\end{abstract}

Keywords: Forward-looking reaction functions; Term structure of interest rates; Expectations model

JEL classification: E44; E52; F41

\section{Introduction}

The empirical failure of the expectations theory of the term structure of interest rates is generally attributed either to systematic expectations errors, or to shifts in the risk premia (see the textbook treatment in Campbell et al., 1997, Chapter 10). In this paper we concentrate on the short end of the term structure, considering the behaviour of 3- and 6-month interest rates, to explicitly analyze the importance of uncertainty in monetary policy in explaining the failure of the expectations model.

Expectations errors on short-term interest rates are usually related to peso problems or to their very low predictability. In a famous study, Mankiw and Miron (1986), using data on a 3 and 6 month maturity, found evidence in favour of the expectation theory prior to the founding of the Federal Reserve System in 1915. Interestingly, they show that the shift in regime occurred with the founding of the Fed led to a remarkable decrease in the predictability of short-term interest rates. Rudebusch (1995) and Balduzzi et al. (1997), expands on this evidence by looking at more recent data.

*Corresponding author. Tel.: +39-2-5836-3306; fax: +39-2-5836-3302.

E-mail address: carlo.favero@uni-bocconi.it (C.A. Favero). 
The claim of very low predictability of policy rates contradicts a growing body of empirical literature which has established interest rate rules as a convenient way to model and interpret monetary policy. An interest rate rule relates the setting of a short-term money market rate (such as the Federal Funds rate in the US) to a central bank's perception of the inflation and output gaps. Taylor (1993), from which this literature originates, simply postulated a plausible rule, and found that it accurately describes how monetary policy actually has been conducted over the period 1987-1992. The original work by Taylor has been refined in a number of papers by Clarida et al. (1998, 1999, 2000), who have shown that a forward-looking version of the Taylor-rule with some interest rates persistence not only track the data well but is also capable of explaining the high inflation in the seventies in terms of an accommodating behaviour towards inflation in the pre-Volcker era. We propose to assess explicitly the role of mis-prediction on monetary policy by estimating jointly a forward-looking interest rate rule, determining the 3-month rates given macroeconomic conditions, and an expectations model, determining the 6-month rates given current and expected future 3-month rates. As both equations in our model are forward looking, we apply GMM as the most natural approach to the solution of our estimation problem.

\section{Interest rate rules and the short-end of the term structure of interest rates: evidence from the US}

Our empirical analysis is based on the estimation of the following model:

$$
\begin{aligned}
r_{t, t+3}= & (1-p)\left[\bar{r}+a_{1} E_{t}\left(\pi_{t+12}-\pi^{*}\right)+a_{2} E_{t}\left(y_{t}-y_{t}^{*}\right)\right] \\
& +\rho r_{t-1, t+2}+u_{1 t} \\
r_{t, t+6}= & b_{1}+b_{2} r_{t, t+3}+b_{3} E_{t} r_{t+3, t+6}+u_{2 t}
\end{aligned}
$$

where $r_{t, t+1}$ is the interest rate observed at month $t$ on a zero-coupon bond with maturity at month $t+i, \pi_{t}$ is inflation at time $t$ and $y_{t}$ is output at time $t, \pi^{*}$ is the target level for inflation set by the monetary policy maker and $y^{*}$ is the natural level of output.

The first equation in the model is a standard forward-looking Taylor rule with interest rate smoothing, proposed by Clarida et al. (1998, 1999, 2000), and successfully implemented to model monetary policy in a number of industrialized countries. The error term $u_{1 t}$ can be rationalized by considering that central bank applies a partial adjustment model, around a target interest rates, described by the following two equations:

$$
\begin{aligned}
& r_{t, t+3}^{*}=\bar{r}+a_{1} E_{t}\left(\pi_{t+12}-\pi^{*}\right)+a_{2} E_{t}\left(y_{t}-y_{t}^{*}\right) \\
& r_{t, t+3}=r(1-\rho) r_{t, t+3}^{*}+\rho r_{t-1, t+2}+u_{1 t}
\end{aligned}
$$

where $r^{*}$ is the target interest rate and $\bar{r}$ is the equilibrium value for $r^{*}$. Note that, if the central bank is setting policy rates optimally, then $a_{1}$ and $a_{2}$ are convolutions of parameters describing the structure of the economy and parameters describing preferences of the monetary policy maker.

The second equation is consistent with the expectations model of the term structure, which is obtained exactly when $b_{2}=b_{3}=0.5$. The error term $u_{2 t}$ captures random fluctuations in the risk 
premium. The hypothesis of absence of correlation between $u_{2 t}$ and the regressors in the second equation is strong but, as we shall see, testable in the estimation framework we are going to use.

By eliminating the unobserved forecast variables, we obtain the following specification of our model:

$$
\begin{aligned}
r_{t, t+3}= & (1-\rho) \bar{r}+a_{1}(1-\rho)\left(\pi_{t+12}-\pi^{*}\right)+a_{2}(1-\rho)\left(y_{t}-y_{t}^{*}\right) \\
& +\rho r_{t-1, t+2}+\epsilon_{1 t} \\
r_{t, t+6}= & b_{1}+b_{2} r_{t, t+3}+b_{3} r_{t+3, t+6}+\epsilon_{2 t}
\end{aligned}
$$

where

$$
\begin{aligned}
& \epsilon_{1 t}=u_{1 t}-a_{1}(1-\rho)\left(\pi_{t+12}-E_{t} \pi_{t+12}\right)-a_{2}(1-\rho)\left(y_{t}-E_{t} y_{t}\right) \\
& \epsilon_{2 t}=u_{2 t}-b_{3}\left(r_{t+3, t+6}-E_{t} r_{t+3, t+6}\right)
\end{aligned}
$$

Then, since $E_{t}\left[\epsilon_{1 t} \mid \mathbf{I}_{t}\right]=0, E_{t}\left[\epsilon_{2 t} \mid \mathbf{I}_{t}\right]=0$,where $\mathbf{I}_{t}$ includes all the variables in the central bank's information set at the time policy rates are chosen, we have a set of orthogonality conditions which can be used to estimate the parameters of interest by GMM. Moreover, joint estimation, allows to explicitly measure expectations errors on policy rates and assess their role in explaining deviations from the expectations model.

\section{Results}

We consider monthly data for the US economy over the sample 1984:1-1999:5. The data span a period of interest rate targeting by the Fed (see Bernanke and Mihov, 1998) for which ample evidence is available on the empirical success of forward-looking Taylor rules. We consider the following set of orthogonality conditions to implement GMM estimation:

$$
\begin{aligned}
& E_{t}\left[\mathbf{f}_{t} \mid \mathbf{I}_{t}\right]=0 \\
& \mathbf{f}=\left[\begin{array}{l}
r_{t, t+3}-\left[(1-\rho) \bar{r}+a_{1}(1-\rho)\left(\pi_{t+12}-\pi^{*}\right)+a_{2}(1-\rho)\left(y_{t}-y_{t}^{*}\right)-\rho r_{t-1, t+2}\right] \\
r_{t, t+6}-\left(b_{1}+b_{2} r_{t, t+3}+b_{3} r_{t+3, t+6}\right)
\end{array}\right]
\end{aligned}
$$

Several empirical problems have to be solved to implement GMM. First, empirical counterparts have to be specified for $\pi^{*}$ and $y_{t}^{*}$. Following the original choice by Taylor (1993), supported by further empirical evidence in Clarida et al. (1999), we set target inflation at 2\%. We derive instead potential output by applying an Hodrick-Prescott filter (with a smoothing parameter of 14400) to our measure for output, which is seasonally adjusted industrial production. ${ }^{1}$ Second, a set of instruments has to be chosen to mimic the relevant information set $\mathbf{I}_{t}$, we consider lagged policy rates, four lags of inflation, four lags of the output gap, the annual change in commodity price inflation, the annual change in employment in the non-farm sector. Third, given that we have substituted observed values to expected

\footnotetext{
${ }^{1}$ We derive the filtered series by considering a larger sample (1984:1-2000:5) than the one actually used for estimation of our two-equation model (1984:1-1999:5).
} 
values for estimation, we have implemented GMM by using the correction for heteroscedasticity and autocorrelation of unknown form with a lag truncation parameter of 12 and choosing Bartlett weights to ensure positive definiteness of the estimated variance-covariance matrix (see Davidson and MacKinnon, 1993). The results of estimation are reported in Table 1.

The estimation of the Taylor rule on 3-month rates gives standard results, illustrating that the model commonly adopted for the Federal funds rate performs equally well when applied to the 3-month rate. There is a strong persistence, the long-run equilibrium nominal rate is 4.65 which, given that we have set the target for inflation at $2 \%$, delivers an equilibrium real interest rate of 2.65 . The response of 3 -month rate to deviations of inflation from target is higher than one, therefore real 3-month rate are raised in presence of inflationary shocks and a necessary condition for stability of equilibrium at the target level for inflation is satisfied. The point estimate of the response of the 3-month rate to the output gap is slightly higher than those reported in the literature but not significantly different.

The explicit estimation of the relation between the 6-month rate and current and future 3-month rates rejects the expectations model. In fact, the sum of coefficients on current and future 3-month rates adds up to one but the current short-term interest rate is over-weighted with a coefficient of 0.8 and the future short-term interest rate is under-weighted with a coefficient of 0.2 . Such numerical values imply that the change in the short-term rate reacts too little to the lagged spread between long and short rates although, the perverse response, usually found in the empirical literature (see Campbell et al., 1997), generated by a negative relation between current change in short term interest rates and lagged spreads is not compatible with our estimates. The point estimate of the constant in this relation is small and does not differ significantly from zero. The $J$-test for the validity of instruments does not reject the null at the five per cent level, although the tail probability is rather close to 5\%. Therefore, we have no strong evidence of violation of the postulated orthogonality conditions.

The relative strength of our proposed methodology is that it allows a direct assessment of the

Table 1

GMM estimation of $E_{t}\left[\mathbf{f}_{t} \mid \mathbf{I}_{t}\right]=0$, sample 1984:1-1999:5

\begin{tabular}{lcccl}
\hline$f_{1 t}=r_{t, t+3}-\left[(1-\rho) \bar{r}+a_{1}(1-\rho)\left(\pi_{t+12}-\pi^{*}\right)+a_{2}(1-\rho)\left(y_{t}-y_{t}^{*}\right)-\rho r_{t-1, t+2}\right]$ \\
$f_{2 t}=r_{t, t+6}-\left(b_{1}+b_{2} r_{t, t+3}+b_{3} r_{t+3, t+6}\right)$ & \multicolumn{1}{l}{-Statistic } & Probability \\
Coefficient & Estimate & S.E. & $t$-Stal \\
\hline $\bar{r}$ & 4.65 & 0.37 & 12.35 & 0.00 \\
$\rho$ & 0.90 & 0.025 & 35.48 & 0.00 \\
$a_{1}$ & 1.28 & 0.29 & 4.43 & 0.00 \\
$a_{2}$ & 1.12 & 0.24 & 4.59 & 0.00 \\
$b_{1}$ & 0.023 & 0.05 & 0.46 & 0.64 \\
$b_{2}$ & 0.80 & 0.038 & 20.94 & 0.00 \\
$b_{3}$ & 0.20 & 0.036 & 5.36 & 0.00 \\
\hline
\end{tabular}

${ }^{\mathrm{a}}$ S.E. of regression in $f_{1 t}: 0.32$. Mean dependent var in $f_{1 t}: 6.52$. S.E. of regression in $f_{2 t}: 0.19$. Mean dependent var in $f_{2 t}$ : 6.63. $J$-statistic $\chi^{2}(8)=15.189$ (0.055). Instruments: $r_{t-1, t+2}, y_{t-1}, y_{t-2}, y_{t-3}, y_{t-4}, \pi_{t-1}, \pi_{t-2}, \pi_{t-3}, \pi_{t-4}, \Delta_{12} l p c m_{t}$, $\Delta_{12} l e_{t} \cdot y_{t}$ : log of seasonally adjusted industrial production; $y_{t}^{*}$ : HP filtered (smoothing parameter $\left.=14400\right) y_{t} ; \pi_{t}:$ annual CPI inflation; $\pi^{*}: 2 \% ; r_{t, t+3}$ : 3-month Eurodollar rate; $r_{t, t+6}$ : 6-month Eurodollar rate; $\Delta_{12} l p c m_{t}$ : annual change in IMP commodity price index; $\Delta_{12} l e_{t}$ : annual change in employment in non-farm sector. All series are taken from Datastream. 


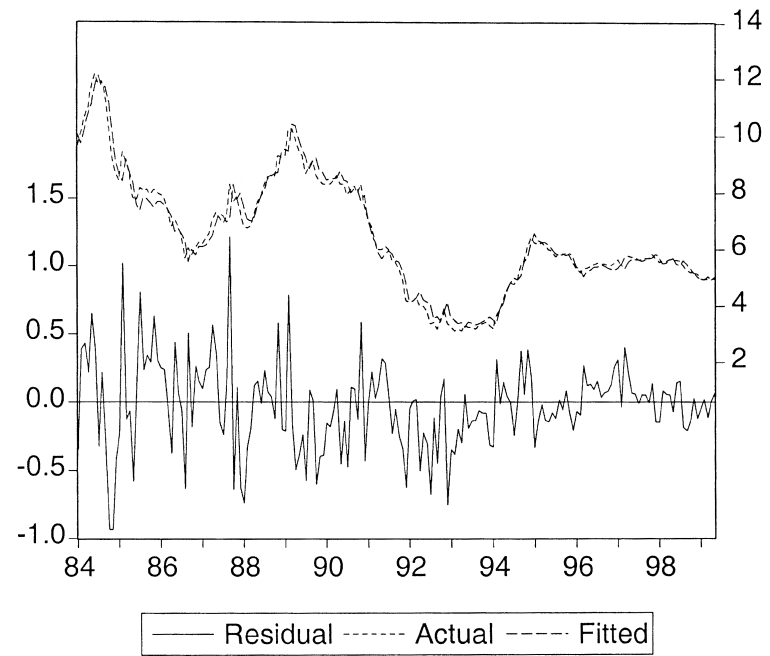

Fig. 1. Actual, fitted values and residuals from the Taylor-rule for 3-month interest rates.

importance of uncertainty on monetary policy and therefore of expectations errors on future short-term rates in explaining deviations from the expectations model. We report in Fig. 1 actual and fitted values and residuals from the estimation of the Taylor rule over the whole sample.

We note that the pre-1994 variance of residuals is clearly higher than the post-1994 variance: after 1994 the uncertainty on monetary policy predicted as predicted by a Taylor rule is clearly reduced. Interestingly, from 1994 onwards the Fed adopted the practice of deciding modifications of the Federal fund target on occasion of the Federal Open Market Committee meetings, whose calendar has been made public in advance. To assess the potential impact of the change in uncertainty on the expectations model we re-estimate the equation for the 6-month interest rates by allowing for a role of uncertainty in determining the response of such-rates to current and future 3-month rates:

$$
\begin{aligned}
r_{t, t+3}= & (1-\rho)\left[\bar{r}+a_{1} E_{t}\left(\pi_{t+12}-\pi^{*}\right)+a_{2} E_{t}\left(y_{t}-y_{t}^{*}\right)\right] \\
& +\rho r_{t-1, t+2}+u_{1 t} \\
r_{t, t+6}= & b_{1}+\left(b_{2}+b_{21} \text { DUM94) } r_{t, t+3}+\left(b_{3}+b_{31} \text { DUM94) } E_{t} r_{t+3, t+6}+u_{2 t}\right.\right.
\end{aligned}
$$

where DUM94 is a dummy variable taking values of 1 from 1994:1 onwards and zero everywhere else. The results from estimation are reported in Table 2.

The estimated modified model shows that uncertainty on monetary policy is capable of explaining totally the deviations from the expectations model observed in our original system. In fact, the weights on current and future short-term rates in the second equation are, respectively, one and zero in the period before 1994, but after 1994 the null of equal weights of one half cannot be rejected, with point estimates lying, respectively, at 0.6 and 0.4. Interestingly, a small but significant constant risk premium of 14 basis points now results from the estimation of the forward-looking model for 6-month rates. 
Table 2

GMM estimation of $E_{t}\left[\mathbf{f}_{t} \mid \mathbf{I}_{t}\right]=0$, sample 1984:1-1999:5

\begin{tabular}{lcccc}
\hline$f_{1 t}=r_{t, t+3}-\left[(1-\rho) \bar{r}+a_{1}(1-\rho)\left(\pi_{t+12}-\pi^{*}\right)+a_{2}(1-\rho)\left(y_{t}-y_{t}^{*}\right)-\rho r_{t-1, t+2}\right]$ \\
$f_{2 t}=r_{t, t+6}-\left(b_{1}+\left(b_{2}+b_{21} D U M 94\right) r_{t, t+3}+\left(b_{3}+b_{31} D U M 94\right)\right.$ & $\left.E_{t} r_{t+3, t+6}\right)$ \\
Coefficient & Estimate & S.E. & $t$-Statistic & Probability \\
\hline $\bar{r}$ & 4.87 & 0.26 & 18.37 & 0.00 \\
$\rho$ & 0.90 & 0.02 & 38.85 & 0.00 \\
$a_{1}$ & 1.09 & 0.22 & 4.78 & 0.00 \\
$a_{2}$ & 0.80 & 0.16 & 4.90 & 0.00 \\
$b_{1}$ & 0.12 & 0.043 & 2.90 & 0.005 \\
$b_{2}$ & 1.00 & 0.048 & 20.94 & 0.00 \\
$b_{21}$ & -0.41 & 0.19 & -2.13 & 0.03 \\
$b_{3}$ & -0.008 & 0.047 & -0.17 & 0.87 \\
$b_{31}$ & 0.40 & 0.19 & 2.13 & 0.03 \\
\hline
\end{tabular}

${ }^{\mathrm{a}}$ S.E. of regression in $f_{1 t}: 0.32$. Mean dependent var in $f_{1 t}: 6.52$. S.E. of regression in $f_{2 t}: 0.16$. Mean dependent var in $f_{2 t}$ : 6.63. $J$-statistic $\chi^{2}(9)=17.76(0.04)$. Wald test $b_{2}+b_{21}=0.5, b_{3}+b_{31}=0.5, \chi^{2}(2)=1.58(0.45)$. Instruments: $r_{t-1, t+2}$, $y_{t-1}, y_{t-2}, y_{t-3}, y_{t-4}, \pi_{t-1}, \pi_{t-2}, \pi_{t-3}, \pi_{t-4}, \Delta_{12} l_{p c m_{t}}, \Delta_{12} l e_{t}, D U M 94 ; y_{t}: \log$ of seasonally adjusted industrial production; $y_{t}^{*}$ : HP filtered (smoothing parameter $\left.=14400\right) y_{t} ; \pi_{t}$ : annual CPI inflation; $\pi^{*}: 2 \% ; r_{t, t+3}: 3$-month Eurodollar rate; $r_{t, t+6}$ : 6-month Eurodollar rate; $\Delta_{12}$ lpcm $_{t}$ : annual change in IMP commodity price index; $\Delta_{12} l e_{t}$ : annual change in employment in non-farm sector; DUM94: dummy variable taking values of one from 1994:1 onwards and 0 everywhere else.

\section{Conclusions}

In this paper we have jointly estimated a forward-looking reaction function for the 3-month rate along with a forward-looking term structure relationship linking the 6-month interest rates to current and expected future 3-month rates. Joint estimation allows measurement of the importance of expectations errors on 3-month rate in explaining deviations from the expectations model. Within our framework, expectations errors on the short-term interest rates reflect directly uncertainty on monetary policy. Estimation of our model on monthly US data over the period 1984-1999, points towards the rejection of the expectations model over the whole sample but also provides evidence for a clear reduction in uncertainty on monetary policy from 1994 onwards. Allowing then for a role of uncertainty of monetary policy in shaping the response of the 6-month interest rates to current and future 3-month interest rate, we find that such a response is fully compatible with the predictions of the expectations model from 1994 onwards.

\section{References}

Balduzzi, P., Bertola, G., Foresi, S., 1997. A model of target changes and the term structure of interest rates. Journal of Monetary Economics 24, 371-399.

Bernanke, B.S., Mihov, I., 1998. Measuring monetary policy. Quarterly Journal of Economics 113 (3), $869-902$.

Campbell, J., Lo, A., MacKinlay, C., 1997. The Econometrics of Financial Markets. Princeton University Press, Princeton.

Clarida R., Gali, J., Gertler, M., 1998. Monetary policy rules in practice:some international evidence. European Economic Review, 42.

Clarida, R., Cali, J., Gertler, M., 1999. The science of monetary policy: A new-Keynesian perspective. Journal of Economic Literature XXXVII (4), 1661-1707. 
Clarida, R., Gali, J., Gertler, M., 2000. Monetary policy rules and macroeconomic stability: evidence and some theory. The Quarterly Journal of Economics 115 (1), 147-180.

Davidson, R., MacKinnon, J.G., 1993. Estimation and Inference in Econometrics. Oxford University Press, Oxford.

Mankiw and Miron, 1986. The changing behaviour of the term structure of interest rates. Quarterly Journal of Economics 101, 211-221.

Rudebusch, G.D., 1995. Federal reserve interest rate targeting, rational expectations, and the term structure. Journal of Monetary Economics 35, 245-274.

Taylor, J.B., 1993. Discretion versus policy rules in practice. Carnegie Rochester Conference Series on Public Policy 39, 195-214. 